\title{
Percutaneous vertebroplasty: Current concepts and local experience
}

\author{
Hwan Tak Hee \\ Division of Spinal Surgery, Department of Orthopaedic Surgery, National University of Singapore, Singapore
}

\begin{abstract}
With the aging population in our country, symptomatic osteoporotic compression fractures are increasingly common. Osteolytic compression fractures from spinal metastasis are also becoming more frequently seen because of the longer life expectancy from improvements in chemotherapy. Percutaneous vertebroplasty with PMMA has been shown to be an efficient procedure to treat pain due to these fractures. It is a minimally invasive procedure performed under local anesthesia and sedation. Injection of PMMA provides immediate stability when it hardens, and permits the patient to ambulate without pain. Appropriate patient selection is the key to clinical success. However, this procedure must be treated with respect, and has to be performed by physicians with the necessary training. Otherwise, increased pain, paralysis, and even death may occur from this seemingly innocuous procedure. In this article, I will deal with the background issues of osteoporotic and osteolytic vertebral compression fractures, patient selection, surgical technique, complications, and review of current literature on vertebroplasty. Key areas of development in this field include the use of kyphoplasty, defining the role of prophylactic augmentation, and improvements in biomaterials.
\end{abstract}

Key Words: Vertebroplasty, compression fractures

\section{Introduction}

With an aging population around the world, osteoporotic and osteolytic vertebral compression fractures are increasingly common. Peak bone mass is obtained by age 35, after which all individuals lose a small amount each year. Half of all women older than 65 have radiographic evidence of osteoporosis, and $90 \%$ are affected by age 75 . The most serious consequence of osteoporosis is the occurrence of pathologic fracture. In the past, osteoporotic compression fractures were often treated with benign neglect, whereas much attention had been paid to the management of osteoporotic hip fractures. The irony is that the number of osteoporotic compression fractures per year in the United States far exceed the number of osteoporotic hip fractures. ${ }^{[1]}$

Though less common than osteoporotic compression fractures, osteolytic vertebral fractures due to metastasis, multiple myeloma, or aggressive benign tumors (e.g. hemangiomas) can be extremely painful, with a clinical presentation not unlike that of osteoporotic compression fractures.

Complications of osteoporotic or osteolytic fractures include spinal cord compression, urinary retention, and ileus. ${ }^{[2]}$ Other complications reported include chronic pain ${ }^{[3]}$ and pulmonary compromise. $^{[4]}$ There is a $9 \%$ loss of predicted forced vital capacity with each vertebral fracture. ${ }^{[4]}$ These patients can suffer considerable physical, functional, and psychosocial impairments manifesting as depression and insomnia. ${ }^{[5]}$ One study showed that osteoporotic compression fractures are associated with $30 \%$ age-adjusted increase in mortality. ${ }^{[6]}$

Traditional treatment of osteoporotic compression fractures include bed rest, analgesics, brace, and gradual mobilization. Unfortunately many patients still have intractable pain and are unable to return to their activities of daily living. This is understandable because medical management fails to restore or prevent worsening of spinal alignment, and the immobility status of the patients can further lead to other complications e.g. atelectasis, pneumonia, decubitus ulcers, deep vein thrombosis, pulmonary embolism, urinary tract infection, and worsening osteoporosis. It is a known fact that one week of prolonged recumbency will result in ten percent loss of bone mass.

In spinal tumors resulting in osteolytic compression fractures, traditional treatment option includes the use of radiotherapy. It has been reported that about fifty percent of patients with spinal metastasis do well with this treatment, particularly with radiosensitive tumors e.g. breast, prostate, and myeloma. However, 
the spine is still prone to progressive osteolytic collapse.

Surgery has been the traditional treatment of choice in osteoporotic and osteolytic compression fractures if the patient fails non-surgical treatment. Surgical approaches may vary from anterior only decompression and instrumentation, posterior only decompression and instrumentation, and combined anteriorposterior surgery (either staged or same day). Indications for surgical intervention are usually reserved for gross spinal deformity or impending neurological deficit. Caution is exercised when recommending surgery because of the adverse risk/benefit ratio in the elderly/cancer population with poor bone stock and co-morbidities.

Vertebroplasty describes a surgical technique using bone graft, cement, or metal implants to modify or reconstruct damaged or destroyed vertebra. This was traditionally done via open surgery. Percutaneous vertebroplasty was first performed by Galibert and Deramond in 1984. They injected PMMA into a C2 vertebra that had been destroyed by an aggressive hamangioma. ${ }^{[8]}$ Dusquenel subsequently used this technique to treat compression fractures associated with osteoporosis and malignancy. ${ }^{[9]}$ In 1993, the technique of percutaneous vertebroplasty was introduced in the United States by Dion and colleagues, and they reported 85 to $90 \%$ significant pain relief for painful osteoporotic compression fractures. ${ }^{[10]}$ Percutaneous vertebroplasty has since grown in popularity to become the standard of care for painful osteoporotic compression fractures of the spine. ${ }^{[11]}$

\section{Patient workup and selection}

Successful results from vertebroplasty require vigorous patient selection. A good history is mandatory, taking particular attention to define whether the compression fractures belong to osteoporotic or osteolytic. A thorough review of body systems, including checking for night pain, fever, loss of weight, loss of appetite, bladder, or bowel changes should be performed. It is helpful to check if the patient has had medical treatment for osteoporosis before. One should also ask for any previous history of cancer, tuberculosis, and other systemic infection. A history of cancer does not always denote that the vertebral fracture is osteolytic, as one third of compression fractures in known malignancy are benign.

Good candidates for vertebroplasty describe a focal, intense, deep pain in the midline of the spine. The pain should be mechanical, i.e. worse with loading and better with recumbency. ${ }^{[12]}$ Vertebroplasty maybe considered if the pain is worsening, or there is a plateau of functional recovery with significant pain remaining. The type of pain i.e. axial versus radicular pain is also important to note, as those with significantly more radicular pain suggests nerve root compression, which may not benefit from vertebroplasty. It is not uncommon to find patients having referred pain, and this finding is not considered a contraindication to vertebroplasty. Some authors advocate placing a metallic marker at the maximal point of tenderness and correlate this fluoroscopically with the anatomical location of the pain. They found the accuracy to be limited to no better than plus or minus one vertebral level in most cases. $^{[13]}$

The time between fracture occurrence and initial consult should be noted. There is no definite exclusion criteria based on the time of the fracture. However, older fractures (more than three months) are less likely to benefit from vertebroplasty. The exceptions to this rule are the presence of nonunion or recurrent fracture. Nonunion is indicated by abnormal persistent motion on fluoroscopy and the finding of a fluid cleft on MRI which shows up as high signal intensity on T2 weighted scans. Nonunion is not infrequently associated with osteonecrosis (Kümmell's disease), which some authors consider a good indication for vertebroplasty. ${ }^{[14]}$ An MRI finding of marrow edema may imply new or recurrent fracture which maybe amenable to vertebroplasty.

Clinical examination should include assessing for spinal deformity and body posture. One may also find associated rib tenderness due to osteoporotic fractures. The pain over the vertebra should increase with flexion, and relieved with extension. Neurological assessment is mandatory since some patients may have "senile burst fractures", which have greater propensity for bony retropulsion leading to neurological deficit.

Good quality imaging is mandatory to allow for proper decision making regarding treatment strategy for these patients. The aims of imaging are several-fold, including extent of vertebral collapse, extent of lytic process, degree of involvement of pedicles, posterior cortical wall breach, central and/or foraminal stenosis, and age of fracture. The initial imaging investigation of choice is plain $\mathrm{x}$ rays. It may be helpful to do an erect x-ray of the whole spine to better evaluate the overall spinal balance of the patient. The number of deformities should be noted. Comparison with previous $\mathrm{x}$-rays is useful as they may demonstrate further collapse. Signs suggestive of posterior wall breach include widening of interpedicular distance and greater than $50 \%$ collapse in height of the vertebra. The level of fractures is important to note, since one study found that fractures occurring above T6 are more likely than not to be neoplastic. ${ }^{[15]}$

Dual energy absorptiometry (DEXA) should be obtained for osteoporotic cases. The data can be used to predict future fracture risks, and can also be used as a baseline for effectiveness of medical treatment of osteoporosis.

Bone scan may help to differentiate the age of the fracture, as a recent fracture will show up as a "hot" spot. However, it does not demonstrate other details e.g. posterior wall integrity, pedicle involvement, presence of paraspinal soft tissue masses which the MRI is able to delineate. For this reason, MRI is now the imaging modality of choice for assessing compression fractures in finer details. Acute fractures will demonstrate edema as decreased T1 and increased T2 or STIR signals (Figure 1). ${ }^{[16]}$ MRI is also useful in differentiating between osteoporotic fractures from pathological fractures due to metastasis or infections. Features suggestive of osteolytic fractures as opposed to osteoporotic fractures are heterogeneous bone marrow appearance, absence of fracture clefts, involvement of pedicles, paraspinal soft tissue 


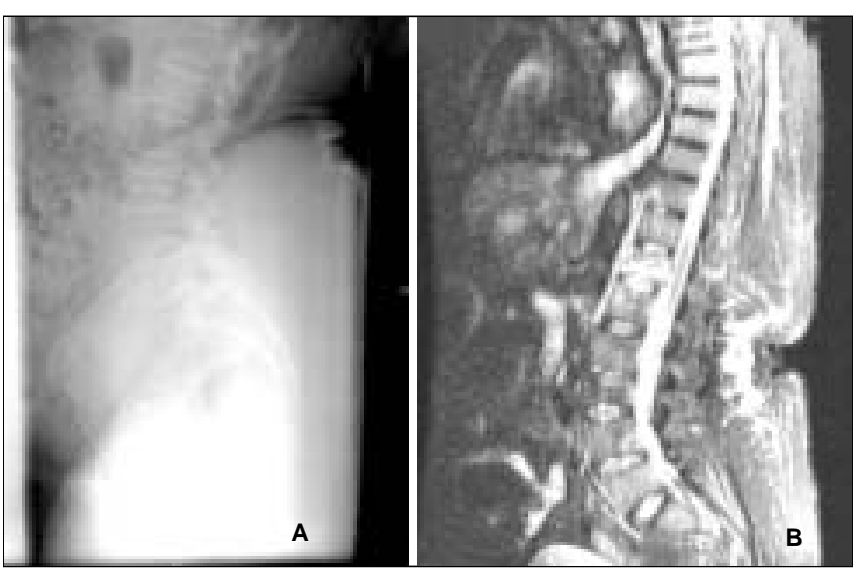

Figure 1: (A) This 67-year old lady sustained a fall at home and had severe low back pain. Plain radiographs showed what appeared to be an obvious L3 compression fracture. (B) However, MRI revealed that her pain is due to an acute fracture at T12 vertebra, manifested by increased T2 signals and fracture cleft in the vertebra. This highlights the importance of obtaining an MRI before one contemplates percutaneous vertebroplasty

extension, epidural extension, and multilevel involvement.

\section{Indications and contraindications}

Persistent pain after occurrence of compression fracture is an indication for vertebroplasty. The question is how long to wait before offering vertebroplasty to these patients. To the best of my knowledge, there is still no consensus to this question. Some authors will persist with conservative treatment (not applicable to osteolytic fractures) for four to six weeks before performing vertebroplasty. ${ }^{[12]}$ In my practice, I am offering vertebroplasty to patients earlier than when I first started performing this procedure. One of the reasons is the significantly good results in terms of pain relief after this procedure. Another is my hypothesis that early aggressive treatment of vertebral compression fractures may prevent progressive kyphosis and its sequelae. ${ }^{[17]}$

Continuing collapse of the fractured vertebra on follow-up, especially with concomitant pain, is also an indication for vertebroplasty. Other fracture patterns that may benefit from vertebroplasty are those occurring at the thoraco-lumbarjunction, those greater than 30 degrees kyphosis, and those with presence of vacuum shadow in the vertebra signifying ischemic necrosis. There is currently no role for prophylactic vertebroplasty except at the ends of long posterior spinal instrumentation to prevent "topping-off syndrome".

There are several contraindications to performing vertebroplasty. Presence of neurological deficit is a contraindication, since any cement leakage albeit minor, may lead to catastrophic neurological deficit. Younger patients (younger than 65 years of age) are also not advised to undergo this procedure for two reasons. First, these patients do have the capability for bony healing, and they should not be denied the opportunity for the fracture to unite. Vertebroplasty will prevent the fracture from healing. Secondly, we still do not know the long-term effects of PMMA in the vertebrae. Perhaps the future lies in the improvement of biomaterials e.g. biodegradable and bioabsorbable materials.
Pregnant patents should not undergo vertebroplasty since they are young, and this procedure needs fluoroscopy. Allergy to any of the materials used in vertebroplasty, presence of coagulopathy, active systemic infection, and severe cardiopulmonary compromise to the extent that the patient is unable to lie prone are also contraindications for vertebroplasty.

High velocity injuries leading to burst fractures, chance fractures, or fractures-dislocations are contraindications to vertebroplasty, as they are more appropriately treated with traditional surgery.

Technical reasons e.g. vertebra plana or severe vertebral collapse (> 70\% reduction in height) ${ }^{[18]}$ posterior cortical wall disruption, and presence of osteoblastic tumor may pose a technical challenge in vertebroplasty. As one gets over the learning curve, these may be listed instead as "extended indications" for vertebroplasty. I have performed vertebroplasty on cases with posterior cortical wall breach and osteoblastic tumor. Others no longer routinely consider vertebra plana as a contraindication. ${ }^{[19]}$

\section{Biomechanics}

The most intuitive explanation for the mechanism of pain relief involves simple mechanical stabilization of the fracture. The PMMA stabilizes the vertebral bodies and offloads the facet joints. Another possibility is that analgesia results from local chemical, vascular, or thermal effects of PMMA on nerve endings in surrounding soft tissues. ${ }^{[20]}$ Supporting this theory is that fact that there is lack of correlation between cement volume and pain relief. ${ }^{[21]}$

Restoration of vertebral stiffness and load-bearing capacity is postulated to eliminate painful micromotion in compression fractures. ${ }^{[22]}$ Small amounts of PMMA (14\% fill or $3.5 \mathrm{~cm}^{[2]}$ ) can restore the stiffiness to the previous level. ${ }^{[23]}$ Less cement is required to restore strength; more cement is required to restore stiffness. ${ }^{[24]}$ Larger vertebral bodies require more cement for restoration of strength and stiffness, though complete fill is not needed. Similar clinical results are attained for both uni- and bi-pedicular PMMA fill of the vertebral bodies. Recent studies have focused on new biomaterials e.g. bioresorbable cements. Most are able to restore mechanical integrity of the vertebral body in vitro. ${ }^{[25]}$

One concern about vertebroplasty is the possible increased adjacent fracture risk by placing a hard material in closed proximity to osteoporotic bone of the adjacent levels. One study showed that vertebrae adjacent to a treated level had an odds ratio of 2.27 for fracture versus 1.44 odds ratio for vertebrae in the vicinity of an uncemented fractured vertebra. ${ }^{[26]}$ However, if there is correction of spinal deformity by postural reduction during positioning prior to vertebroplasty, the procedure may actually reduce the risk of adjacent level fracture by restoring the spinal column to a more physiologic alignment. This also explains why a modification of vertebroplasty using balloon tamps (kyphoplasty) may reduce the fracture risk at adjacent levels as inflation of the tamps will restore lost vertebral height of the fractured vertebra.

\section{Technique}

Vertebroplasty is usually performed under local anesthesia and 
sedation, with close monitoring of the patients' parameters by the anesthesiologist. The preferred sedation used in my institution consists of 3 to 4 milligrams of midazolam and 50 to 100 micrograms of fentanyl. Prophylactic antibiotic (1 gram of cefazolin) is routinely given since this procedure involves injecting foreign material (PMMA) into the body. I prefer to use a completely radiolucent table (e.g. Jackson OSI table illustrated in Figure 2) so that the C-arm has complete access in performing true AP and lateral images of the spine, which is critical to the success of the procedure. Degenerative scoliosis and spinal metastasis with destroyed pedicles may impair proper visualization of the pedicles. Some authors (usually radiologists) prefer to perform vertebroplasty under CT guidance. ${ }^{[19]}$ The patient is initially placed prone on the table. Patients who cannot tolerate this position for an hour may not be suitable candidates for vertebroplasty under local anesthesia. Performing vertebroplasty under general anesthesia maybe the next best option, but the major disadvantages are the risk of general anesthesia in these elderly patients and the inability to gather verbal feedback from the patients regarding leg symptoms should there be cement extravasation into the spinal canal.

The operative field is subsequently cleaned and draped in a sterile fashion. Localization of the pedicles is performed with the aid of the fluoroscopy. Local anesthesia is subsequently given from the skin, subcutaneous layer, and the periosteum of the bone at the bone entry site. A $0.5 \mathrm{~cm}$ paramedian incision is made on either side of the spine, for insertion of the 11 gauge trocar-cannula system. The most frequently used route is the transpedicular. This is a familiar route for surgeons used to placement of pedicle



Figure 2: (A) Illustrates the radiolucent Jackson OSI table used in vertebroplasty, as well as patient/C-arm positioning. (B) Note the 2 needle trocars in place for a bipedicular approach to the vertebral body screws. It also offers several advantages over the parapedicular route. First of all, the pedicle provides a definite anatomical landmark for needle targeting. Secondly, it is an effective route for vertebroplasty and biopsy of lesions (osteolytic fractures) inside the vertebra. Thirdly, it does not carry the danger of needle damage to adjacent structures e.g. nerve root and lung, as long as one maintain an intrapedicular route throughout.

The parapedicular approach may be useful in the middle to upper thoracic spine where the pedicles may be small and unable to accommodate the standard 11 gauge trocar-cannula system. This approach allows the needle tip to be angled more toward the center of the vertebra than the transpediclar route. This may allow easier filling of the vertebra with a single needle. The inherent dangers lie in iatrogenic damage to surrounding structures mentioned earlier. It is also harder to tamponade any paraspinous hematoma formed after needle removal from the lateral side of the vertebral body.

Using the transpedicular route, the needle is centered at the 10 o'clock over the left pedicle and 2 o'clock over the right pedicle on the $\mathrm{AP}$ view with the help of a long needle holder, thus avoiding radiation to the surgeon's hands. One may have to start the entry point slightly more superior so that the needle is able to traverse the vertebral body without penetrating the fractured and collapsed superior end plate. The needle should also be medialized through the cylinder of the pedicle to reach the middle of the vertebra. Once a footprint is obtained by the needle in the pedicle, and the position is considered ideal on the AP view, advancement of the needle will be done under the guidance of the lateral fluoroscopy (Figure 3). In osteoporotic bone, penetrating the bony cortex and advancing the needle into the vertebral body is easy. In contrast, the bone in osteoblastic tumor may be hard and dense, except where it is destroyed by tumor. One may consider in this scenario to use a mallet to advance the needle rather than manual manipulation. The tip of the needle should lie beyond the midpoint of the vertebral body on the lateral view. The ideal endpoint is the junction between the anterior and middle thirds of the vertebral body, since this area is relatively devoid of venous plexuses.

I routinely place two needles into the vertebral body i.e. bipedicular approach even though clinical results are reportedly similar with single versus double-needle approach. ${ }^{[27]}$ There are
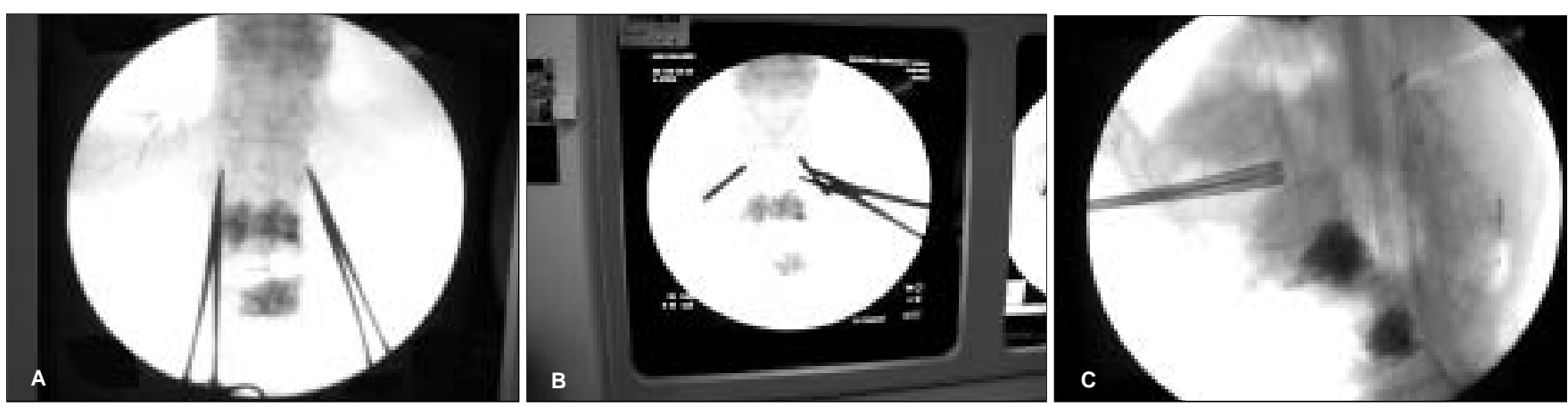

Figure 3: Illustrates the technique of needle placement of L1 vertebra under the guidance of the C-arm. Vertebroplasty had already been performed at L3 and L2 vertebrae. (A) Entry points marked using tips of hemostats. (B) AP fluoroscopic view demonstrating trocars introduced into the pedicles bilaterally. (C) Lateral fluroscopic view guiding the depth of the trocars 
several advantages of the two needle technique. I am more confident of a complete vertebral fill using this technique. The second cannula may act as a "vent" during cement injection through the other cannula, reducing the risk of cement extravasation. I can terminate injection through one cannula if there is cement leakage on fluoroscopy, and move on to the other cannula without the worry about not being able to achieve a complete vertebral fill.

Venogram or vertebrogram is used next to identifiy potential leak sites (particularly into the spinal canal via the epidural venous plexus), which if present, may warrant adjustment of the needle position (Figure 4). The commonly used agents are omnipaque 300 or isovue 300. Some authors have found no benefits from using venogram/vertebrogram because the contrast material and the bone cement differ greatly in viscosity. ${ }^{[28]}$ Others have found no added benefits in terms of increasing the safety of the procedure with the use of venogram. ${ }^{[29]}$ Nevertheless, I still find venography necessary and useful in my practice. If there is no significant extravasation on venography, I am very confident that there will be no cement leakage during cement injection.

Cement is prepared when the position of the needles is ideal and there is no significant extravasation on venography. Cement with adequate opacification (barium or tantalum beads) is used so that injection can be monitored in real time to detect any extravasation. It is shown that barium sulfate in quantities of about $30 \%$ by weight mixed with PMMA will provide adequate opacification. ${ }^{[30]}$ Certain cement e.g. Simplex P only contains $10 \%$ by weight of barium. Therefore, additional barium should be added to obtain adequate opacification. I will remove about one teaspoon of cement powder $(10 \mathrm{ml})$, and substitute with one teaspoon (6 grams) of barium.Current cement manufactured for vertebroplasty e.g. spineplex (Stryker) and cranioplastic (Johnson and Johnson) contain sufficient barium for the purpose of vertebroplasty.

One can slow the polymerization and thus increase the working time by chilling the cement once mixed. Syringes to be used for

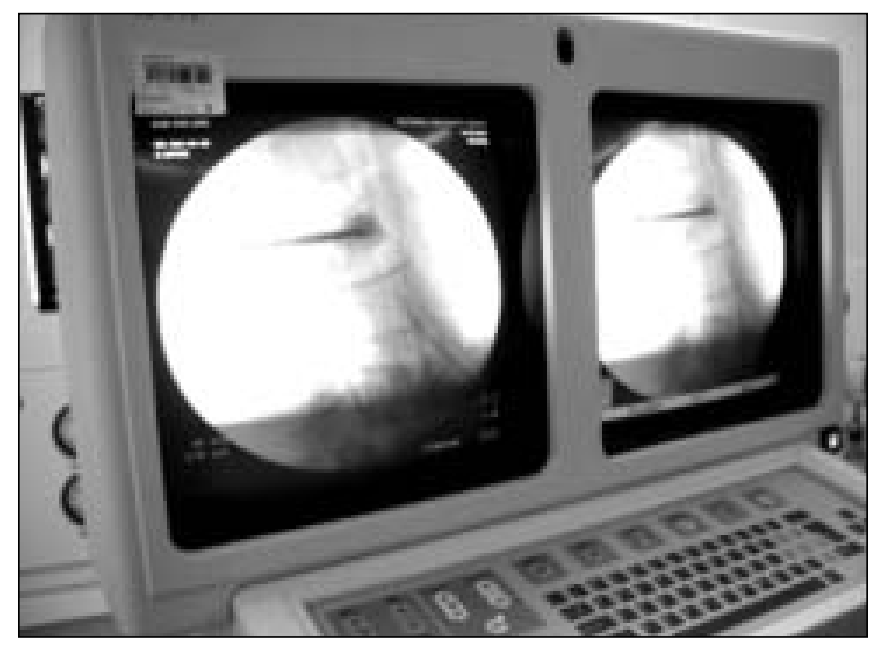

Figure 4: Venography being carried out to confirm that there was no significant leakage of the injected dye (omnipaque or isovue) injection are placed in sterile cold cardioplegic colution. Using monomer which has been chilled at near $0^{\circ} \mathrm{C}$ for 24 hours or more can also slow the polymerization of the cement.

Some authors will routinely add tobramycin to the PMMA before injection. I rely more on prophylactic intravenous antibiotic and maintenance of sterility throughout the procedure. I prefer closed vacuum mixing of the cement as this maintains a sterile environment. Open mixing increases the chance of cement contamination and reduces the cement strength by inclusion of air bubbles.

One should inject the cement when it is no longer in a liquid consistency, in order to minimize the risk of extravasation. The cement injection should be monitored real time or small amounts $(0.1$ to $0.2 \mathrm{ml})$ and the result verified before further cement injection takes place. This is done under the guidance of lateral Carm image. I usually work through one cannula first before moving to the second cannula. This preserves a route for subsequent injection should a leak be discovered. Moving to the second cannula will complete the vertebral fill without further leak as the original leak will be occluded by the initial cement, which will have hardened. Additional amounts of cement can be delivered by pushing the trocar into the cannula, allowing a further $0.9 \mathrm{ml}$ cement per cannula (11 gauge) to be introduced into the vertebra.

The amount of cement required to produce pain relief is still uncertain. One study performed in vitro showed that prefracture stiffness and strength can be restored by 2.5 to $4 \mathrm{ml}$ of cement in the thoracic vertebra, and 6 to $8 \mathrm{ml}$ in the lumbar vertebra. ${ }^{[31]}$ This amounts to 50 to $70 \%$ fill of the residual volume of the compressed vertebra. Significant strength restoration can be provided with a unipedicular approach if the cement filling crosses the midline of the vertebra. ${ }^{[32]}$

The maximum number of levels to be injected at one setting is also not determined. According to one author, there is no limit as to the number of levels that can be performed, especially if the patient is under general anesthesia. ${ }^{[33]}$ However, the current consensus by most experts is that no more than three levels should be attempted at one setting. This minimizes the risk of hemodynamic compromise to the patient from micro-embolization (cement and fat emboli) that may not be apparent from fluoroscopy. The risk of cement leakage is almost twice in osteolytic fractures as compared to osteoporotic compression fractures, and thus I will recommend that this rule be even more stringently applied to spinal metastasis.

After injection of cement is completed, the patient is kept prone until the cement completely hardens. I will rest the patient in bed for the rest of the day, and only start ambulation the following day. This is especially so for the slower setting cement e.g. cranioplastic.

\section{Pitfalls and complications}

The complications encountered with vertebroplasty can be related to anesthesia, misplacement of instruments, cement extravasation, adjacent level fracture, and infection. 
Cement leakage can occur via fracture clefts, improper instrument position, or vertebral venous plexus. This can be overcome by high quality imaging, adequate barium for opacification, and slow application of PMMA in a viscous state. The cement leakage rate is approximately $6 \%$ in osteoporotic compression fractures ${ }^{[26]}$ and $10 \%$ in metastasis. ${ }^{[34]}$ Cement leakage into adjacent disc space via a pre-existing fracture cleavage plane that extends into the disc space may greatly increase the risk of adjacent level fractures. The rate of asymptomatic leak into the disc space and spinal canal varies from $0-65 \% .^{[10,16,19,26,27,34]}$ The disc normally is the least stiff structure in the spinal column, and helps to dissipate the stress. Leakage of cement into the disc will stiffen up the disc and therefore increases the chance of adjacent level fracture.

The risk of neurological sequelae ranges from 0-4\% according to various reports. ${ }^{[10,16,19,26,27,34]}$ Cement leaking from the vertebra adjacent to a nerve root may produce radicular pain. Analgesics, local steroid and anesthetic injections should provide adequate relief, provided there are no motor deficits (including bladder and bowel). CT scan on an emergent basis should be arranged if there are significant motor deficits, and is usually associated with large volume leaks resulting in neurological compression.

Cement leakage via the venous system has also been associated with pulmonary embolism. ${ }^{[10]}$ These are usually not symptomatic, but may rarely produce clinical symptoms accompanying pulmonary infarct. With a right to left shunt, this may result in the development of cerebral infarct. ${ }^{[35]}$

Complication rate is considerably higher in spinal metastasis due to lytic areas involving the vertebral cortex and the propensity for cement leakage into the surrounding tissues (estimated at $10 \%$ ). Because the introduction of cement involves pushing marrow out of the intertrabecular space, there is concern about fat emboli as well as cement emboli.

\section{Clinical Results}

There are currently no randomized prospective trials evaluating the efficacy of vertebroplasty. Evans conducted a prospective evaluation of 72 patients pre- and post-vertebroplasty, and found substantial lasting reduction in pain and improvement in ability to perform activities of daily living. ${ }^{[36]}$ Zoarski presented a prospective non-randomized study of the effectiveness of vertebroplasty in relieving pain. ${ }^{[37]}$ Utilizing the musculoskeletal outcomes data evaluation and management scale (MODEMS), 22 out of 23 cases improved and remained satisfied during 15 to 28 month follow-up.

In our institution, we have performed vertebroplasty on 27 patients with a minimum of 2 years follow-up. There were 23 cases of osteoporotic compression fractures (Figure 5). There were 4 cases of spinal metastasis (Figure 6 ) leading to osteolytic compression fractures (2 breast and 2 lung). The male to female ratio was 1:4. Nineteen patients had single level fractures; five had double level fractures; three had triple level fractures. The total number of levels injected was 35. Three levels had to be abandoned due to persistent leakage on venography despite adjustment of needle position. Seven injected levels were performed via a uni-pedicular approach due to persistent dye extravasation through the contralateral pedicle. The length of hospital stay ranged from 1-27 days (mean 6 days; median 2 days). At latest follow-up, significant pain relief (defined as decrease of VAS scores of more than $50 \%$ ) was reported in 26 patients (96\%). One patient did not have significant relief because he also had

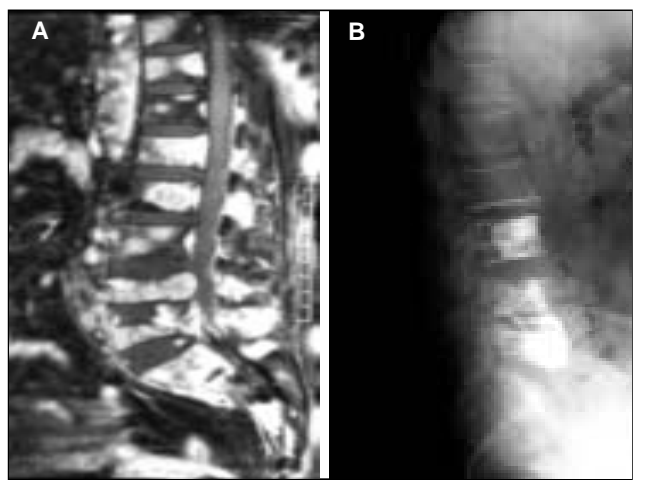

Figure 6: (A) A case of breast carcinoma with multilevel spinal metastasis and symptomatic pathological fractures from L3 to L5 vertebra. (B) Note the extracorporeal cement leak at L4 vertebra


Figure 5: (A) T1 weighted MR image showing T12 body fracture. (B) Post-vertebroplasty AP view. (C) Post-vertebroplasty lateral view 
concomitant sacral insufficiency fracture that was not injected with cement, as we did not have experience in sacroplasty (vertebroplasty in sacrum) at that time. We had one case who developed congestive heart failure after vertebroplasty, and had to be managed in the ICU for 5 days. He had carcinoma of the lung with metatstasis to L2 vertebra. He also had poor cardiac function with an ejection fraction of only $26 \%$. We noted three cases of cement extrusion: intradiscal (1), extra-corporeal (1), and neural foramen (1). The extracorporeal leak was due to inadvertent penetration of the anterior border of the L4 vertebra in a case of osteolytic breast metastasis in L3 to L5 vertebrae (Figure 6). There was one case of cement leak into the intervertebral foramen T12L1 on the right. The leak was not apparent on plain radiographs, and the patient was asymptomatic till 4 months later when she presented with sudden weakness of both legs. MRI of the spine was ordered which revealed the above-mentioned finding (Figure 7). Her weakness spontaneously improved after a week.

Favorable results have also been reported using vertebroplasty to manage spinal metastasis. Alvarez reported his experience with vertebroplasty in vertebral tumors. ${ }^{[38]}$ In his series, he found excellent results in $66 \%$, decreased pain in $22 \%$, and no change in $12 \%$ of his patients. He would not perform vertebroplasty if there is evidence of epidural compression and/or if the posterior wall of the vertebra is not intact on the side of the vertebroplasty. Fourney reported significant pain relief over time in his patients who had painful vertebral body fractures secondary to cancer spread. ${ }^{[39]}$ In his series, the absence of cement leakage-related complications probably reflects the use of high-viscosity cement, kyphoplasty in selected cases, and relatively small amounts of cement injected.

A recent study examined predictors of outcome of percutaneous vertebroplasty for osteoporotic vertebral fractures. ${ }^{[0]}$ They found better results to be expected in patients with American Society of Anesthesiologists score of 1 and when the vertebral level managed is confirmed by MRI, and the vertebral body height loss is less than $70 \%$.

The future advances in vertebroplasty will probably come from

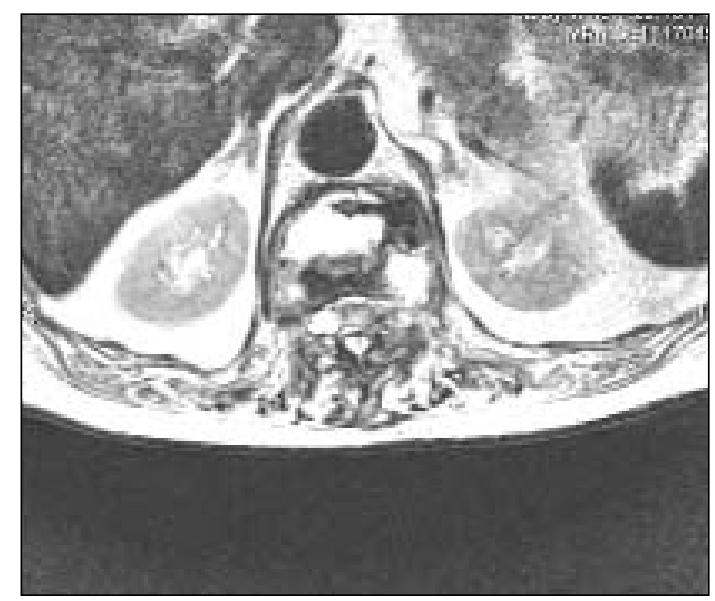

Figure 7: Cement leak in the intervertebral foramen of T12L1 on the right evident only on MRI improvements in biomaterials. Although PMMA is widely used in vertebroplasty with good clinical results, they are not ideal. They are not bioabsorbable and biocompatible, and cannot participate in any bony healing. Exothermic reaction of PMMA can cause thermal necrosis to surrounding soft tissues. Any significant cement leakage can have deleterious clinical consequences. Monomer toxicity is also an issue that the physician has to contend with. Newer substitutes are currently being on trial and may offer viable alternatives to PMMA in the future. Examples are calcium sulfate cement and calcium phosphate cement (CPC). These cements are biocompatible, osteoconductive, euthermic, and are bioabsorbable. One study recently examined vertebral augmentation with calcium sulfate cement in osteoporotic compression fractures. ${ }^{[41]}$ They found similar strength and stiffiness between the use of calcium sulfate and PMMA. The degree of restoration of strength and stiffness was greater than expected. They concluded that the lower potential stiffness of calcium sulfate may reduce the complications of adjacent level fractures. They may also be suitable agents for the incorporation of growth factors that facilitate bony ingrowth.

Another paper evaluated the use of calcium phosphate cement (CPC) in vertebroplasty. ${ }^{[42]}$ They found reliable early relief of pain with this procedure. However, maintenance of pain relief and kyphosis is not encouraging. Union rate was $80 \%$, with the remaining $20 \%$ still exhibiting intravertebral clefts. They concluded that CPC alone may not offer sufficient anterior column support.

\section{Conclusion}

Osteoporotic and osteolytic vertebral compression fractures pose significant clinical problems including spinal deformity, pain, reduced pulmonary function, reduced mobility, and overall increase in mortality. Traditional forms of treatment maybe ineffective in some cases. However, without level 1 evidence establishing the benefits of vertebroplasty over conservative treatment in osteoporotic compression fractures, the majority of these fractures should initially be managed conservatively. Conducting prospective randomized studies comparing radiotherapy versus vertebroplasty may be difficult in osteolytic fractures secondary to metastasis, as their lifespan may be limited. Nevertheless, in carefully selected cases, percutaneous vertebroplasty has been shown to be very efficacious in relieving the pain associated with both osteoporotic and osteolytic compression fractures. It is a relatively noninvasive procedure that has gained widespread acceptance as the standard of care for compression fractures unresponsive to traditional forms of treatment. Higher chance of complications is expected for vertebroplasty in spinal metastasis, and part of this drawback arises because of the toxicity and poor handling characteristics of PMMA, rather than the procedure itself. Future advances lie in kyphoplasty, which is a modification of vertebroplasty. It is a higher margin of safety since it is associated with a lower cement leakage rate. Other areas of progress may lie in defining the role of prophylactic augmentation and development 
of synthetic osteoconductive composites to replace PMMA.

\section{References}

1. Melton LJ. Epidemiology of vertebral fractures in women. Am J Epidemiol 1989;129:1000-11.

2. Bostrom MP, Lane JM. Future directions. Augmentation of osteoporotic vertebral bodies. Spine 1997;15:38-42.

3. Cooper C, Atkinson EJ, O'Fallon WM, Melton LJ. Incidence of clinically diagnosed vertebral fractures: a population-based study in Rochester, Minnesota, 1985-1989. J Bone Miner Res 1992;7:221-7.

4. Leech JA, Dulberg C, Kellie S, Pattee L, Gay J. Relationship of lung function to severity of osteoporosis in women. Am Rev Respir Dis 1990;141:68-71.

5. Lyles KW, Gold D'T, Shipp KM, Pieper CF, Martinez S, Mulhausen PL. Association of osteoporotic vertebral compression fractures with impaired functional status. Am .J Med 1993;94:595-601.

6. Kado DM, Browner WS, Palermo L. Vertebral fractures and mortality in older women: a prospective study. Study of osteoporotic fractures research group. Arch Intern Med 1999;159:1215-20.

7. Sundaresan N, Krol G, Digiacinto G, Hughes J. Metastatic tumors of the spine; in Sundaresan N, Schmidek HH, Schiller AL, Rosenthal D (eds): Tumors of the Spine; Diagnosis and clinical management. London: Saunders; 1990. p. 279-304.

8. Galibert P, Deramond H, Rosat P, Le Gars D. Preliminary note on the treatment of vertebral angioma by percutaneous acrylic vertebroplasty. Neurochir $1987 ; 33: 166-8$

9. Lapras C, Mottolese C, Deruty R, Lapras C Jr, Remond J, Duquesnel J. Percutaneous injection of methyl-methacrylate in osteoporosis and severe vertebral osteolysis (Galibert's technique). J Ann Chir 1989;43:371-6.

10. Jensen ME, Evans A.J, Mathis JM, Kallmes DF, Cloft HJ, Dion JE. Percutaneous polymethylmethacrylate vertebroplasty in the treatment of osteoporotic vertebral body compression fractures: technical aspects. A.JNR Am J Neuroradiol 1997;18:1897-904

11. Mathis JM, Barr JD, Belkoff SM. Percutaneous vertebroplasty: a developing standard of care for vertebral compression fractures. A.JNR Am J Neuroradiol $2001 ; 22: 373-81$.

12. Truumees E, Hilibrand A, Vaccaro AR. Percutaneous vertebral augmentation. The Spine J 2004;4:218-29.

13. Mathis JM. Percutaneous vertebroplasty; in Mathis JM (editor): Image-guided spine interventions. New York: Springer; 2004. p. 245-72.

14. Jensen ME, Dion JE. Percutaneous vertebroplasty in the treatment of osteoporotic compression fractures. Neuroimaging Clin N Am 2000;10:547-68.

15. Tamayo-Orozeo J, Arzac-Palumbo P, Peon-Vidales H, Mota-Bolfeta R, Fuentes F. Vertebral fractures associated with osteoporosis: patient management. Am .J Med 1997;103:44S-8S.

16. Cyteval C, Sarrabere MP, Roux JO. Acute osteoporotic vertebral collapse: open study on percutaneous injection of acrylic surgical cement in 20 patients. Am J Roentgenol 1999;173:1685-90.

17. Hee HT. Vertebroplasty - local experience. Presented at minimally invasive spinal surgery workshop. Hong Kong: August 2004.

18. Cotten A, Boutry N, Cortet B. Percutaneous vertebroplasty: state of the art. Radiographies 1998;18:311-20.

19. Barr JD, Barr MS, Lemley T.J, MeCann RM. Percutaneous vertebroplasty for pain relief and spinal stabilization. Spine 2000;25:923-8.

20. Mathis JM, Petri M, Naff N. Percutaneous vertebroplasty treatment of steroidinduced osteoporotic compression fracture. Arthritis Rheum 1998;41:171-5.

21. Dean JR, Ison KT, Gishen P. The strengthening effect of percutaneous vertebroplasty. Clin Radiol 2000;55:471-6.

22. Belkoff SM, Mathis JM, Fenton DC, Scribner RM, Reiley ME, Talmadge K. An ex vivo biomechanical evaluation of an inflatable bone tamp used in the treatment of compression fracture. Spine 2001;26:151-6.

23. Liebschner MA, Rosenberg WS, Keaveny TM. Effects of bone cement volume and distribution on vertebral stiffness after vertebroplasty. Spine 2001;26:1547-54

24. Heini PF, Berlemann U, Kaufmann M. Augmentation of mechanical properties in osteoporotic vertebral bodies - a biomechanical investigation of vertebroplasty efficacy with different bone cements. Eur Spine J 2001;10:164-71.

25. Belkoff SM, Mathis .JM, Jasper LE, Deramond H. An ex vivo biomechanical evaluation of a hydroxyapatite cement for use with vertebroplasty. Spine 2001;26:1542-6.

26. Grados F, Depriester C, Cayrolle G. Long-term observations of vertebral osteoporotic fractures treated by percutaneous vertebroplasty. Rheumatology (Oxford) $2000 ; 39: 1410-4$.

27. Kim AK, Jensen ME, Dion .JE, Unilateral transpedicular percutaneous vertebroplasty: initial experience. Radiology 2002;222:737-41.

28. Wong W, Mathis JM. Commentary: is intraosseous venography a significant safety measure in performance of vertebroplasty? J Vase Intervent Radiol 2002;13:1378.

29. Gaughen JR, Jensen ME, Schweickert PA. Relevance of antecedent venography in percutaneous vertebroplasty for the treatment of osteoporotic compression fractures. A.JNR Am J Neuroradiol 2002;23:594-600.

30. Jasper L, Deramond H, Mathis JM, Belkoff SM. Material properties of various cements for use with vertebroplasty. .J Mater Sci Mater Med 2002;13:1-5.

31. Belkoff SM, Mathis JM, Jasper LE. The biomechanies of vertebroplasty: the effect of cement volume on mechanical behavior. Spine 2001;26:1537-41.

32. Tohmeh AG, Mathis JM, Fenton DC, Levine AM, Belkoff SM. Biomechanical efficacy of unipedicular versus bipedicular vertebroplasty for the management of osteoporotic compression fractures. Spine 1999;24:1772-6.

33. Martin JB. Cementoplasty. Presented at minimally invasive spinal surgery workshop. Hong Kong: August 2004.

34. Deramond H, Depriester C, Galibert P, Le Gars D. Percutaneous vertebroplasty with polymethylmethacrylate:technique, indications, and results. Radiol Clin North Am 1998;36:533-46.

35. Scroop R, Eskridge J, Britz GW. Paradoxical cerebral arterial embolization of cement during intraoperative vertebroplasty: case report. A.JNR Am J Neuroradiol 2002;23:868-70

36. Evans AJ, Kip KE, Boutin SM. Evaluation of 72 patients pre and post vertebroplasty:a prospective study. The Spine .J 2004:4:45-6.

37. Zoarski GH, Snow P, Olan WJ. Percutaneous vertebroplasty for osteoporotic compression fracture: quantitative prospective evaluation of long-term outcomes. J Vase Intervent Radiol 2002;13:139-48.

38. Alvarez L, Perez-Higueras A, Rossi RE, Calvo E. Vertebroplasty in the treatment of vertebral tumors. Eur Spine .J 2001;10:125.

39. Fourney DR, Schomer DF, Nader R, Chlan-Fourney J, Suki D, Ahrar K, et al. Percutaneous vertebroplasty and kyphoplasty for painful vertebral body fractures in cancer patients. J Neurosurg Spine 2003;98:21-30.

40. Álvarez L, Pérez-Higueras A, Granizo JJ, de Miguel I, Quinones D, Rossi RE. Predictors of outcomes of percutaneous vertebroplasty for osteoporotic vertebral fractures. Spine 2005;30:87-92.

41. Perry A, Kim C, Mahar A, Arrieta N, Massie J, Wayne A, et al. Biomechanical evaluation of vertebral augmentation with calcium sulfate cement in cadaveric osteoporotic vertebral compression fractures. The Spine J 2004;4:46-7.

42. Ishida T, Hashimoto T, Shigenobu K, Kanavama M, Oha F, Yamane S. Clinical results of vertebroplasty for osteoporotic vertebral collapse with a minimum of 1 year follow up:percutaneous transpedicular injection of calcium phosphate cement under local anesthesia. The Spine J 2004;4:84. 